\title{
MY LIFE WITH THINGS
}
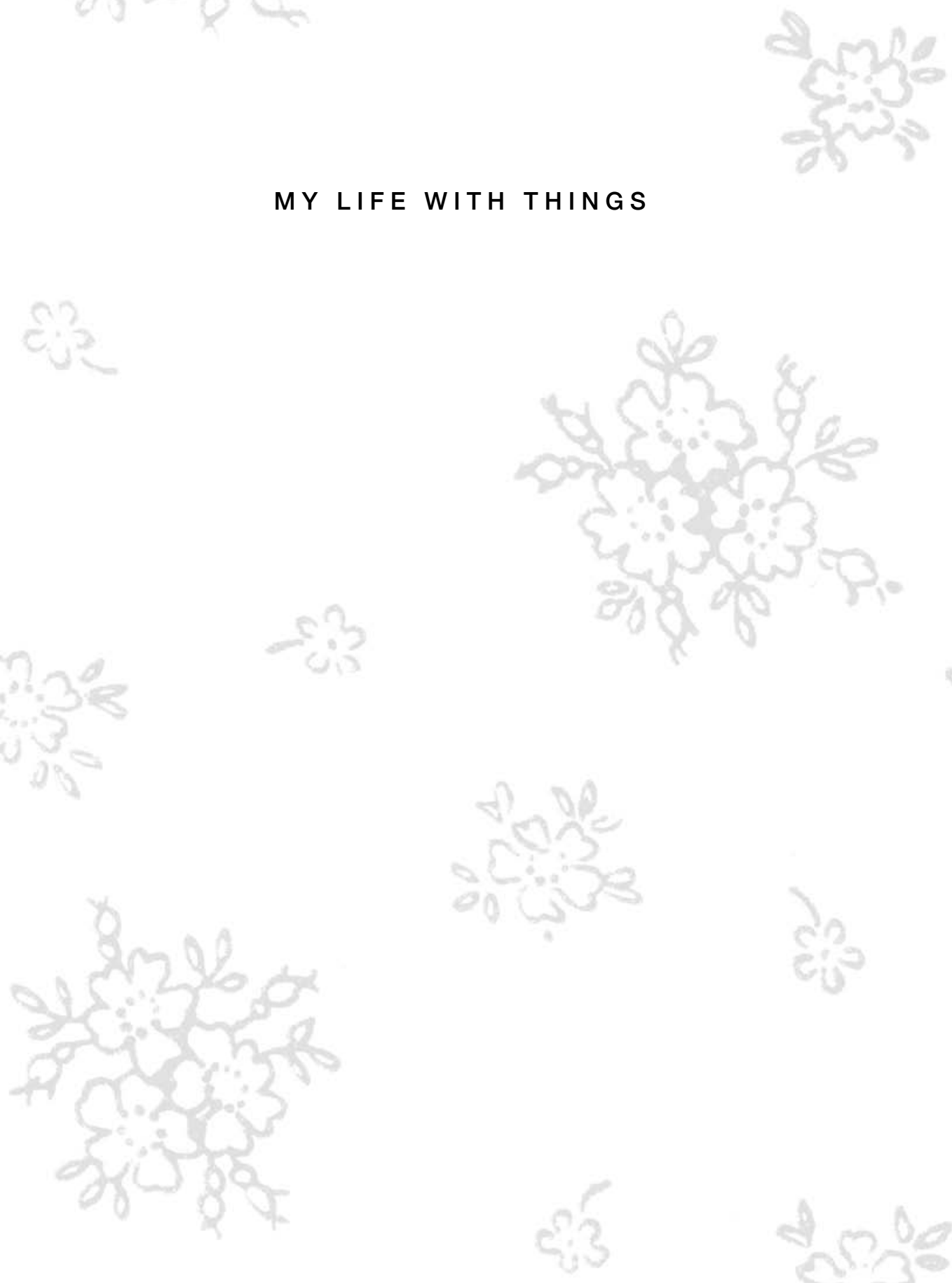



\section{MY LIFE WITH THINGS}

The Consumer Diaries ELIZABETH CHIN

DUKE UNIVERSITY PRESS Durham and London 2016 
(C) 2016 DUKE UNIVERSITY PRESS •

ALL RIGHTS RESERVED • PRINTED

IN THE UNITED STATES OF AMERICA

ON ACID-FREE PAPER • DESIGNED

BY NATALIE F. SMITH - TYPESET IN

QUADRAAT BY GRAPHIC COMPOSITION,

INC. BOGART, GEORGIA • LIBRARY OF

CONGRESS CATALOGING-IN-PUBLICATION

DATA • NAMES: CHIN, ELIZABETH,

[DATE] AUthoR. - TITLE: My LIFE WITH

THINGS: THE CONSUMER DIARIES /

ELIZABETH CHIN. DESCRIPTION:

DURHAM : DUKE UNIVERSITY PRESS,

2016. I INCLUDES BIBLIOGRAPHICAL

REFERENCES AND INDEX. •

IDENTIFIERS: LCCN 2015042545 |

\section{- ISBN 9780822361183}

(HARDCOVER : ALK. PAPER) • ISBN

9780822361367 (PBK. : ALK. PAPER)

- ISBN 9780822374268 (E-BOOK)

- SUBJECTS: LCSH: CONSUMERS -

DIARIES. I ANTHROPOLOGISTS-

DIARIES. I CHIN, ELIZABETH,

1963 -DIARIES. I ETHNOLOGY-

AUTHORSHIP. | CONSUMPTION

(ECONOMICS) | CONSUMER

BEHAVIOR. - CLASSIFICATION: LLC

HF5415.32.C4562016|DDC 306.3-

DC23 - LC RECORD AVAILABLE

AT HTTP://LCCN.LOC.GOV/2015042545 